\title{
The effect of intellectual ability on functional activation in a neurodevelopmental disorder: preliminary evidence from multiple fMRI studies in Williams syndrome
}

\author{
Jennifer R Pryweller ${ }^{1,2^{*}}$, Suzanne N Avery ${ }^{3}$, Jennifer U Blackford ${ }^{2,4,5}$, Elisabeth M Dykens ${ }^{2,5,6}$ \\ and Tricia A Thornton-Wells ${ }^{2,7}$
}

\begin{abstract}
Background: Williams syndrome (WS) is a rare genetic disorder caused by the deletion of approximately 25 genes at 7q11.23 that involves mild to moderate intellectual disability (ID). When using functional magnetic resonance imaging (fMRI) to compare individuals with ID to typically developing individuals, there is a possibility that differences in IQ contribute to between-group differences in BOLD signal. If IQ is correlated with BOLD signal, then group-level analyses should adjust for IQ, or else IQ should be matched between groups. If, however, IQ is not correlated with BOLD signal, no such adjustment or criteria for matching (and exclusion) based on IQ is necessary.

Methods: In this study, we aimed to test this hypothesis systematically using four extant fMRI datasets in WS. Participants included 29 adult subjects with WS (17 men) demonstrating a wide range of standardized IQ scores (composite IQ mean $=67, \mathrm{SD}=17.2$ ). We extracted average BOLD activation for both cognitive and task-specific anatomically defined regions of interest (ROIs) in each individual and correlated BOLD with composite IQ scores, verbal IQ scores and non-verbal IQ scores in Spearman rank correlation tests.

Results: Of the 312 correlations performed, only six correlations (2\%) in four ROls reached statistical significance at a $P$ value $<0.01$, but none survived correction for multiple testing. All six correlations were positive. Therefore, none supports the hypothesis that IQ is negatively correlated with BOLD response.

Conclusions: These data suggest that the inclusion of subjects with below normal IQ does not introduce a confounding factor, at least for some types of fMRI studies with low cognitive load. By including subjects who are representative of $\mathrm{IQ}$ range for the targeted disorder, findings are more likely to generalize to that population.
\end{abstract}

Keywords: IQ, BOLD fMRI, Williams syndrome, Intellectual disability

\section{Background}

Williams syndrome (OMIM\#194050) is a rare neurodevelopmental disorder caused by a hemizygous microdeletion on chromosome 7 (7q11.23), involving approximately 25 genes $[1,2]$. The neurocognitive profile of individuals with Williams syndrome (WS) is characterized by weakness in visuospatial construction alongside relative strengths in

\footnotetext{
*Correspondence: Jen.Pryweller@Vanderbilt.edu

'Interdisciplinary Studies in Neuroimaging of Neurodevelopmental Disorders, Vanderbilt University Medical Center, Nashville, TN, USA

${ }^{2}$ Vanderbilt Kennedy Center for Research on Human Development,

Vanderbilt University, Nashville, TN, USA

Full list of author information is available at the end of the article
}

verbal short-term memory, expressive language, and face processing [3-6]. The personality profile of individuals with WS is marked by non-social anxiety and fears, hypersociability, and heightened empathy [7-11]. Individuals with WS frequently demonstrate a strong attraction to music and a fascination with certain sounds, paired with auditory hypersensitivity (hyperacusis) and phonophobia [12-17]. It has been suggested that maladaptive emotional and behavioral responses to environmental stimuli in persons with WS might be related to increased non-social anxiety, fear, and arousal or to sensory modulation impairments $[8,18-20]$. Functional neuroimaging

\section{Biomed Central}


studies in WS have aimed to investigate several aspects of the WS phenotype.

Although there is considerable inter-individual variability, most studies indicate mild to moderate intellectual disability in individuals with WS, reporting a range of IQ scores from 40 to 100 , with a mean between 50 and 60 (see Table 1) [21-24]. Though the significance and size of the difference is still debated, studies consistently find verbal IQ is greater than non-verbal IQ in WS [22,24-26], which is consistent with the neurocognitive profile $[4,23,27]$. When using functional magnetic resonance imaging (fMRI) to compare individuals with ID to typically developing individuals, there is a possibility that differences in IQ contribute to between-group differences in blood oxygen level-dependent (BOLD) signal. If IQ were correlated with BOLD signal, then group-level analyses should adjust for IQ, or else IQ should be matched between groups. If, however, IQ is not correlated with BOLD signal, no such adjustment or criteria for matching (and exclusion) based on IQ is necessary.

To date, approximately 18 published functional magnetic resonance imaging (fMRI) studies compare a WS sample to typically developing controls [28-45]. Six of the 18 studies restricted their recruitment of participants with WS to those who had an IQ within approximately one standard deviation of normal for the general population (see Table 2) [31-33,38,40,42]. With a mean IQ of 60 , only $4.5 \%$ of those with WS have an IQ in this range, leading one-third of published studies to exclude a representative $95.5 \%$ of the WS population. This raises concerns about the generalizability of study findings to the majority of people with WS. Although some of the studies using this exclusion criterion were focused on using WS as a model to understand a particular aspect of the WS neurocognitive profile, at a minimum, this highlights a gap in research that is aimed at understanding WS per se as opposed to only specific components of the syndrome. In this study, we aimed to examine the relationship between IQ and BOLD activation using four extant fMRI datasets in WS. We hypothesized that in taskrelated studies with low cognitive load, IQ would not be correlated with BOLD activation.

\section{Methods}

\section{Subjects}

The extant datasets used for this analysis were drawn from four small fMRI studies conducted over a 6-year period. Participants included 29 individuals with WS (17 men, three left-handed) aged 16 to 59 years (mean $=25.2, \mathrm{SD}=8.4$ ) recruited from the annual Vanderbilt Kennedy Center's Williams Syndrome Music Camp, sponsored by the Vanderbilt Kennedy Center for Research on Human Development. Because scan acquisition was ongoing over several years, some campers participated in more than one fMRI study (see Additional file 1 Table S1 for participant enrollment by study).

We used multiple techniques in an effort to minimize participant anxiety about the MRI scan. To avoid anxiety related to the unfamiliar sounds they would hear during their MRI, an audio CD was recorded with the fulllength sound that each imaging sequence would make during the scan session, and a copy of the $\mathrm{CD}$ was sent to each new participant prior to his or her attendance at Music Camp. During camp, participants interacted with imaging research staff, and prior to their actual scan, they were exposed to a mock MRI scanner that looked identical to the real one but did not contain the magnet. They were given the opportunity to lie down on the scanner bed and listen to the scanner sounds again. We also employed one participant with WS as a peer mentor. This mentor had successfully completed MRI scans with us in previous years and could to talk to his peers about his experience. Each participant gave his or her informed assent, and the participant's parent or guardian gave informed consent prior to each study. Study protocols were approved by the Vanderbilt University Medical Center Institutional Review Board.

\section{Intellectual assessment}

The Kaufman Brief Intelligence Test, Second Edition (KBIT-2), a brief measure of verbal and non-verbal intelligence, was administered to each participant. Standard scores (typical population: mean $=100, \mathrm{SD}=15$ ) for verbal and non-verbal domains, as well as an IQ composite, are obtained. The KBIT-2 was developed for

Table 1 Intellectual ability in Williams syndrome

\begin{tabular}{|c|c|c|c|c|c|c|c|c|c|}
\hline \multirow[t]{2}{*}{ Author (year) } & \multirow[t]{2}{*}{$n$} & \multirow[t]{2}{*}{ Age (years) } & \multirow[t]{2}{*}{ Measure } & \multicolumn{2}{|l|}{ FSIQ } & \multicolumn{2}{|l|}{ VIQ } & \multicolumn{2}{|l|}{ PIQ } \\
\hline & & & & Mean & (Range) & Mean & (Range) & Mean & (Range) \\
\hline Boddaert et al. (2006) & 9 & $5-15$ & WISC-III & 63 & (50-79) & 76 & $(62-91)$ & 53 & $(43-65)$ \\
\hline Don et al. (1999) & 18 & $8-13$ & WISC-III & 52 & $\mathrm{nr}$ & 61 & $(46-81)$ & 50 & $(45-62)$ \\
\hline Howlin et al. (1998) & 62 & $19-39$ & WAIS-R & 60 & $\mathrm{nr}$ & 64 & $\mathrm{nr}$ & 60 & $\mathrm{nr}$ \\
\hline Pagon et al. (1987) & 9 & $10-20$ & WISC-R & 42 & $(40-75)$ & 54 & $(45-85)$ & 52 & $(45-69)$ \\
\hline Reiss et al. (2004) & 43 & $12-50$ & WISC-R, WAIS-R & 68 & $(46-83)$ & $\mathrm{nr}$ & $\mathrm{nr}$ & $\mathrm{nr}$ & $\mathrm{nr}$ \\
\hline Searcy et al. (2004) & 80 & $17-52$ & WAIS-R & 67 & $\mathrm{nr}$ & 71 & $\mathrm{nr}$ & 66 & $\mathrm{nr}$ \\
\hline
\end{tabular}

For each study, participant ages, IQ measure, full scale IQ (FSIQ), verbal IQ (VIQ), and performance IQ (PIQ) are listed. nr, not reported. 
Table 2 WS fMRI studies using low IQ as exclusion criterion for WS participants

\begin{tabular}{|c|c|c|c|c|c|c|c|}
\hline Author (year) & fMRI task(s) & Group & $n$ & Sex & Age (SD) & IQ measure & $\begin{array}{l}\text { IQ composite } \\
\text { mean (SD) }\end{array}$ \\
\hline \multirow{2}{*}{$\begin{array}{l}\text { Meyer-Lindenberg } \\
\text { et al. (2004) }\end{array}$} & \multirow{2}{*}{$\begin{array}{l}\text { Visual processing tasks (1. Passive } \\
\text { viewing; } 2 \text {. Visuospatial matching/ } \\
\text { constructive; 3.Visual attention) }\end{array}$} & WS & $13^{\mathrm{a}}$ & $6 \mathrm{M}, 7 \mathrm{~F}$ & $28.3(9.6)$ & WASI (short form) & $92.1(9.6)$ \\
\hline & & $C T L$ & 11 & $6 \mathrm{M}, 5 \mathrm{~F}$ & $30.8(7.6)$ & WAIS-R (short form) & $96.8(6.5)$ \\
\hline \multirow{2}{*}{$\begin{array}{l}\text { Meyer-Lindenberg } \\
\text { et al. (2005a) }\end{array}$} & \multirow{2}{*}{$\begin{array}{l}\text { Visual matching (stimuli = faces, } \\
\text { scenes, shapes) }\end{array}$} & WS & 9 & $3 \mathrm{M}, 6 \mathrm{~F}$ & $31.6(9.6)$ & $\mathrm{nr}$ & $92.4(7.8)$ \\
\hline & & CTL & 10 & $6 \mathrm{M}, 4 \mathrm{~F}$ & $29.0(4.9)$ & $\mathrm{nr}$ & $97.5(6.4)$ \\
\hline \multirow{2}{*}{$\begin{array}{l}\text { Meyer-Lindenberg } \\
\text { et al. (2005b) }\end{array}$} & \multirow{2}{*}{$\begin{array}{l}\text { Passive viewing (stimuli = faces, } \\
\text { houses, scrambled) }\end{array}$} & WS & $13^{\mathrm{a}}$ & $6 \mathrm{M}, 7 \mathrm{~F}$ & $28.3(9.6)$ & WASI (short form) & $92.1(9.6)$ \\
\hline & & $C T L$ & $11^{\mathrm{b}}$ & $6 \mathrm{M}, 7 \mathrm{~F}$ & $28.3(9.6)$ & WAIS-R (short form) & $97.9(7.6)$ \\
\hline \multirow[t]{2}{*}{ Muñoz et al. (2010) } & \multirow{2}{*}{$\begin{array}{l}\text { Visual/Emotional processing tasks } \\
\text { (1. Emotional content labeling; } \\
\text { 2. Scenes matching; 3. Shape matching) }\end{array}$} & WS & $13^{\mathrm{a}}$ & $6 \mathrm{M}, 7 \mathrm{~F}$ & $28.3(9.62)$ & WASI (short form) & $92.1(9.6)$ \\
\hline & & $C T L$ & $11^{* *}$ & $6 \mathrm{M}, 5 \mathrm{~F}$ & $30.8(7.6)$ & WAIS-R (short form) & $97.9(7.6)$ \\
\hline \multirow[t]{2}{*}{ Olsen et al. (2009) } & \multirow{2}{*}{$\begin{array}{l}\text { Passive viewing (stimuli = checkerboard, } \\
\text { expanding ring; with button press) }\end{array}$} & WS & 10 & $5 \mathrm{M}, 5 \mathrm{~F}$ & $31.3(9.0)$ & WASI (short form) & $92.1(8.8)$ \\
\hline & & CTL & 10 & $3 \mathrm{M}, 7 \mathrm{~F}$ & $29.3(5.0)$ & WAIS-R (short form) & $96.2(7.4)$ \\
\hline \multirow[t]{2}{*}{ Sarpal et al. (2008) } & \multirow{2}{*}{$\begin{array}{l}\text { Passive viewing (stimuli = faces, } \\
\text { houses, scrambled) }\end{array}$} & WS & 9 & $6 \mathrm{~F}, 3 \mathrm{M}$ & $31.6(\mathrm{nr})$ & $\mathrm{nr}$ & $92.4(\mathrm{nr})$ \\
\hline & & CTL & 10 & $4 \mathrm{M}, 6 \mathrm{~F}$ & $29(\mathrm{nr})$ & $\mathrm{nr}$ & $97.5(n r)$ \\
\hline
\end{tabular}

Eighteen Williams syndrome (WS) fMRI studies use typically developing controls (CTL) as a contrast group. These six of the 18 studies exclude WS participants with low IQ.

${ }^{a}$ The same group of WS participants was used in these studies.

${ }^{\mathrm{b}}$ The same group of control participants was used in these studies.

nr, not reported; WAIS-R, Wechsler Adult Intelligence Scale - Revised (Wechsler, 1981); WASI, Wechsler Abbreviated Scale of Intelligence (Wechsler, 1999).

research or screening purposes in persons aged 4 years through adulthood. K-BIT2 scores correlate highly with other IQ tests and have been used successfully in WS and other samples with IDD [46,47]. Administration is brief, accommodating a population that presents functional or behavioral challenges that would otherwise preclude the use of a longer intellectual assessment.

\section{Data acquisition}

Functional MR images (time of repetition $(\mathrm{TR})=2,000 \mathrm{~ms}$, time to encode $(\mathrm{TE})=35 \mathrm{~ms}$, flip angle $=79^{\circ}, 3.5-\mathrm{mm}$ slice thickness with a $0.35-\mathrm{mm}$ gap, $240 \mathrm{~mm}^{2}$ field of view, $1.875 \times 1.875 \times 3.85 \mathrm{~mm}^{3}$ voxel size, sensitivity encoding (SENSE) factor $=1.5$ ) were acquired using a singleshot T2-weighted gradient-echo echo-planar sequence, sensitive to changes in BOLD contrast. Slices were acquired parallel to the anterior-posterior commissural line $(\mathrm{AC}-\mathrm{PC})$ with an $80 \times 80$ pixel image matrix, reconstructed to $128 \times 128$ pixels. The number of functional MR image slices in each volume varied slightly by taskrelated study (as described below): Aud-MNS (33 slices), Music-Noise (31 slices), Faces (32 slices), Images (32 slices). High-resolution T1-weighted (T1W) anatomical volume images were acquired at the same location $\left(\mathrm{TR}=4.6 \mathrm{~ms}, \mathrm{TE}=9 \mathrm{~ms}, 256 \mathrm{~mm}^{2}\right.$ field of view, $1 \times 1 \times$ $1 \mathrm{~mm}^{3}$ voxel size, 170 sagittal slices). All images were obtained using a Philips Achieva 3-Tesla MRI scanner (Philips Healthcare, Inc., Best, The Netherlands).

Visual stimuli for fMRI tasks were rear-projected onto a translucent screen placed above the head coil and viewed through a double mirror attached to the head coil. Binaural auditory stimuli were delivered through the scanner's pneumatic auditory stimulation system via standard Philips headphones. The presentation of audiovisual stimuli, controlled through E-Prime Software (Psychological Software Tools, Pittsburgh, PA, USA), was synchronized with data acquisition by a trigger pulse delivered by the scanner console.

\section{Study design and stimuli}

The extant datasets used for this analysis were drawn from four smaller fMRI studies conducted over a 6-year period.

\section{Auditory mirror neuron system study (Aud-MNS)}

We obtained stereophonic sounds from the International Affective Digital Sounds (IADS) database, and we selected 20 sounds for auditory stimuli, which we classified into one of four groups: hand actions, mouth actions, laughter, or environment. Hand actions, mouth actions, and laughter sounds were selected as stimuli likely to activate the human mirror neuron system (MNS), and environmental sounds were selected as stimuli that were unlikely to activate the MNS. To avoid misinterpretation of auditory stimuli, participants were familiarized with the sounds during a practice task prior to the scan. The practice task consisted of presenting each of the auditory stimuli on a computer while the participant viewed a white fixation cross on a black screen. Following two successive presentations of each sound, the fixation cross disappeared, and a description of the stimulus sound was displayed on the screen. The description of each sound was read to the participant out loud. 
The Aud-MNS study employed a block design with four passive-listening stimulus conditions: hand action sounds, mouth action sounds, laughter sounds, and environmental sounds, plus a silent/rest condition. Each stimulus block was comprised of five (6 s) conditionspecific auditory stimuli. Each of three Aud-MNS runs consisted of eight 30-s blocks (two blocks of each stimulus condition) interleaved with 10-s silent/rest condition blocks (344 s/run). The presentation of stimulus blocks was counterbalanced within and across the three runs, and auditory stimuli were randomized within single blocks. During the scan, as in the training task, participants were asked to focus on a white fixation cross that appeared on a black background in the center of the visual display during auditory stimulus presentation. For $500 \mathrm{~ms}$ after each silent/rest condition, a white asterisk symbol was displayed in place of the fixation cross to cue the beginning of a new stimulus block. The primary contrast of interest was action (hand and mouth) sounds versus non-action (environmental) sounds, which were previously shown to evoke mirror neuron system activation $[48,49]$.

\section{Music-Noise study}

The Music-Noise study consisted of two runs, inclusive of four auditory stimulus conditions: single musical notes, single musical chords, human non-word vocalizations, and white noise. Presentation of 12 auditory stimuli, for $2 \mathrm{~s}$ each, was randomized within in each stimulus condition block. Within a single run, following the presentation of four consecutive stimulus blocks, one of each condition, was a 24-s silent/rest condition. A white fixation cross was displayed in the center of a black screen during all stimulus and silent/rest conditions. Three presentations of each stimulus block were included in each of two consecutive runs. In preliminary analyses for the Music-Noise study, each sound condition was contrasted with the silent condition. However, since each of the three sound conditions (notes, chords, human vocalizations) elicited similar brain activation patterns, we simplified the primary contrast of interest to sound versus silence [43]).

\section{Faces study}

In the Faces study, participants were asked to passively view two runs of face stimuli consisting of three stimulus conditions: happy, sad, and angry faces. Each of nine stimulus condition blocks contained 10 stimuli presented for $2 \mathrm{~s}$ each, followed by a 10-s silent/rest condition. A white fixation cross was displayed in the center of a black screen during all stimulus and silent/rest conditions. Stimuli were randomized within blocks, and blocks were randomized within each run. For the Faces task, the primary contrast of interest was angry faces versus fixation, which is known to elicit a very robust fear or anxiety-related response and was previously reported to produce different levels of activation in individuals with WS versus typical development [44,50,51].

\section{Images study}

In the Images study, participants were asked to passively view two runs of 'Images' stimuli, which did not include images of humans. Nine blocks, presented in each of two consecutive runs consisted of three stimulus conditions: positive, negative, and neutral images. Each stimulus condition block presented 10 stimuli for $2 \mathrm{~s}$ each and was followed by a 10 -s silent/rest condition. A white fixation cross was displayed in the center of a black screen during all stimulus and silent/rest conditions. Stimuli were randomized with each run and stimulus condition blocks were balanced across the presentation of the two runs. The primary contrast of interest was negative versus neutral images, which was chosen to reveal differences in brain activation related to fear processing or anxiety.

\section{Image processing}

We performed a series of preprocessing corrections on the fMRI data: slice time correction, 3D motion correction, 3D spatial smoothing (6 mm FWHM Gaussian kernel), and linear trend removal. Data found to exceed 3 $\mathrm{mm}$ of translation or 3 degrees of rotation during a single time-series were excluded from the analysis. We registered fMRI images to T1W structural images from the same participant and transformed all images to Talairach space.

To measure changes in BOLD response, a randomeffects general linear model (GLM) with separate study (run) predictors was applied to each individual's fMRI data for each task.

Each of the four extant datasets we used had its own study-specific hypotheses, contrasts, and regions of interest (ROIs), which we included in this post-hoc analysis (Sections 2.4.1-4). An additional set of ROIs was specified for analysis across all four studies to test for potential effects of IQ on BOLD activation in 14 primary cognitive regions of the brain [52]. Unilateral ROIs specified for cognitive regions included: anterior cingulate gyrus, cingulate gyrus, posterior cingulate gyrus, superior frontal gyrus, medial frontal gyrus, inferior frontal gyrus, and middle frontal gyrus. All ROIs were defined anatomically using the Talairach-Tournoux Atlas dataset from AFNI (TTatlas+tlrc Dataset; Cox, 1996). A full-list of study-specific and cognitive ROIs can be found in Additional file 2 Table S2. Beta coefficient values for each ROI were derived from study-specific GLM analyses. All image analysis, including data preprocessing, GLM, and ROI analyses, was performed in Brain 
Voyager QX Software (version 1.9; Brain Innovation, Maastricht, The Netherlands).

\section{Analyses}

In this study, we aimed to address the interpretation of study-specific ROI activations in the context of studyspecific hypotheses. We also investigated whether there were any IQ-related effects in primary cognitive brain regions. In contrast, a whole brain analysis approach would have been more appropriate for a study designed to identify whole brain patterns associated with variability in IQ. To evaluate the relationship between functional activation and intellectual ability, we performed correlation analyses. For each fMRI study, a two-tailed Spearman rank correlation test (IBM SPSS Statistics Software, version 19) was conducted to evaluate the relationship between fMRI contrast-specific $\beta$-values, measured for each subject in each ROI, and his or her KBIT-2 scores (composite IQ score, verbal IQ score, non-verbal IQ score).

Using a liberal experiment-wise Type I error rate of 0.01 , the Bonferroni-corrected $\alpha$ for each study was given by the number of ROIs within the study (AudMNS: 28 ROIs, $\alpha=0.00036$; Music-Noise: 24 ROIs, $\alpha=0.00042$; Faces: 26 ROIs, $\alpha=0.00038$; Images: 26 ROIs, $\alpha=0.00038$ ). These tests were conducted for all participants in a study ('All Subjects'). Table 3 shows subject enrollment and group mean IQ scores for each of the four

Table 3 Study enrollment and group mean IQ scores

\begin{tabular}{llll}
\hline fMRI study & IQ measure & Mean \pm SD & (n) \\
\hline Auditory MNS study & & \\
& Composite & $69.3 \pm 20.9$ & (16) \\
& Verbal & $76.3 \pm 18.7$ & (16) \\
& Non-verbal & $67.6 \pm 21.6$
\end{tabular}

Music-Noise study

$\begin{array}{ll}\text { Composite } & 70.1 \pm 19.2 \\ \text { Verbal } & 80.4 \pm 14.7 \\ \text { Non-verbal } & 66.1 \pm 20.6\end{array}$

Faces study

$\begin{array}{ll}\text { Composite } & 71 \pm 15.9 \\ \text { Verbal } & 69.2 \pm 20.0 \\ \text { Non-verbal } & 79.2 \pm 11.8\end{array}$

Images study
Subject enrollment is shown for each of four fMRI tasks performed. KBIT-2 IQ scores (mean \pm SD) are reported for subjects enrolled in each task. The All Subjects group, which includes all participants in a task, was stratified into Low IQ (<1 SD below normal) and High IQ (within 1 SD of normal) subject groups based on scores for each IQ measure given by the KBIT-2: composite, verbal, and non-verbal. studies. In total, we conducted 312 'All Subjects' Spearman rank correlation tests (4 studies $\times 24-28$ brain ROIs per study $\times x 3$ IQ measures). Since the three IQ measures are intercorrelated, we chose to correct for only one set of IQ measures (Table 3).

\section{Results}

\section{Intellectual assessment}

There were no significant differences between verbal and non-verbal IQ scores using a two-tailed Student's $t$ test. However, consistent with the WS phenotype, the group mean of verbal standard scores was higher than that of non-verbal standard scores.

\section{Correlation analyses}

To assess the effect of IQ on BOLD activation in studyspecific regions of interest, we performed correlation analyses. None of the Spearman rank correlation coefficients $(\rho)$ from any of the 312 tests were significant at their respective $\alpha$ level in a two-tailed test. Because our sample size (and therefore our power) in each study was limited, we also wanted to know whether any correlations reached an effect size large enough to be detected in an fMRI study with as many as 26 total subjects (13 per group), which is larger than any of the previously published studies on WS. Such a study would be powered to detect a nominally significant correlation of $\mathrm{r}=0.58$ at an uncorrected $P<0.01$. Of the 312 correlations, seven $(5.4 \%)$ had effect sizes $(\rho)$ of at least 0.58 . These seven correlations were found in five ROIs. In the right fusiform gyrus, $\beta$-values from the Images task positively correlated with IQ composite scores $(\rho=0.727$, $P<0.007)$ and verbal standard scores $(\rho=0.734$, $P<0.007)$. In the left insula, $\beta$-values from the Faces task positively correlated with non-verbal standard scores $(\rho=0.746, P<0.003)$. Also in the Faces study, significant correlations were found in two cognitive ROIs: in the right anterior cingulate, $\beta$-values positively correlated with IQ composite $(\rho=0.728, P<0.005)$ and nonverbal standard $(\rho=0.735, P<0.004)$ scores, and in the right inferior frontal gyrus, $\beta$-values positively correlated with IQ composite scores $(\rho=0.700, P<0.008)$. Correlation coefficients for each of these tests showed positive correlations between functional activation and intellectual ability. In the right middle frontal gyrus a significant negative correlation was found for IQ Composite $(\rho=-0.642, P<0.010)$.

\section{Discussion}

Of the 12 published WS fMRI studies that did not exclude participants based on low IQ, one-third $[29,34,36,37]$ performed a correlation analysis to assess the effect of IQ on BOLD activation in both the WS and control groups. All four of these studies reported no 
Table 4 fMRI $\beta$-value vs. IQ rank score correlation analysis results

\begin{tabular}{lllllcc}
\hline ROI & fMRI study & IQ measure & $(\boldsymbol{n})$ & $\boldsymbol{\rho}^{*}$ & Uncorrected $\boldsymbol{P}$ value & Corrected $\boldsymbol{P}$ value \\
\hline Right fusiform gyrus & Images & Composite & $(12)$ & 0.727 & 0.007 & 0.868 \\
& & Verbal & $(12)$ & 0.734 & 0.007 & 0.868 \\
Left insula & Faces & Non-verbal & $(13)$ & 0.746 & 0.003 & 0.372 \\
Right anterior cingulate & Faces & Composite & $(13)$ & 0.728 & 0.005 & 0.620 \\
& & Non-verbal & $(13)$ & 0.735 & 0.004 & 0.496 \\
Right inferior frontal gyrus & Faces & Composite & $(13)$ & 0.700 & 0.008 & 0.992 \\
Right middle frontal gyrus & Music-Noise & Composite & $(15)$ & 0.642 & 0.010 & 1.00 \\
\hline
\end{tabular}

correlation between subject IQ and BOLD activation. In addition, one of the studies that did not exclude participants based on low IQ [39] actually replicated results from two previous studies that did exclude based on IQ [31,42], suggesting IQ does not have an effect on BOLD activation. Likewise, the current study found no significant correlations between IQ and BOLD that survived correction for multiple testing. Additionally, it would be informative to conduct the same analysis in typicallydeveloping individuals.

Each of the fMRI studies we included was designed to target a specific neurocognitive or emotional component of the WS phenotype; however, all involved passive listening and/or viewing of stimuli, with little to no cognitive load. One limitation of these studies is that we did not include eye tracking, button presses, or other attention monitoring strategies to ensure participants were attending to the passive tasks. Some fMRI studies involving a higher cognitive load might elicit brain activation that is negatively correlated with IQ. In this case, including persons with ID in the target sample, but not the control sample, IQ would confound between-group effects. However, it is possible to reduce the cognitive load of some studies without sacrificing construct validity. Future studies should assess the correlation between functional activation and intellectual ability during tasks with higher cognitive load to determine whether participants with ID should be excluded from such studies.

The choice of an appropriate control group and matching criteria is very important and often controversial. For the studies described herein, we were primarily interested in understanding how individuals with WS differ from those with typical development. Given the wide range of intellectual disability in WS, for some fMRI studies that require a higher cognitive load, individuals with other intellectual and developmental disabilities may provide a more appropriate, cognitively matched contrast group to control for potential confounds related to cognitive demand. In future studies, it would also be interesting to investigate these same phenomena in other neurodevelopmental groups with ID, such as Prader-Willi syndrome, autism spectrum disorders, Down syndrome, or Fragile $\mathrm{X}$ syndrome, whose neuropsychological profiles are very different from that of people with WS.

\section{Conclusions}

In this study, we aimed to explore the relationship between IQ and BOLD activation using extant fMRI datasets in WS. Using a liberal correction for multiple testing, none of the correlation coefficients from any of the 312 tests were significant, suggesting functional activation was not correlated with intellectual ability across multiple tasks with low cognitive load. Given that exclusion of subjects based on IQ limits the inferences that can be made about the vast majority of individuals with WS, investigators should consider modifications in study design that would still permit investigation of the scientific questions of interest.

Some reports have found neural activity correlates positively with intellectual ability during tasks of higher cognitive load [52,53], while others have not [29,34,36,37]. Graham et al. (2010) found evidence that the relationship between IQ and BOLD is complex and depends on multiple factors including, which cognitive processes are employed, which brain region are involved, task complexity and experimental design [54]. Thus, it is important to consider modeling IQ in one's analysis, even when the IQ among participants is in the normal range. Based on the findings from this study, we propose that investigators measure IQ and, if the outcome of interest is dependent on IQ, it should be controlled for in the analysis. In summary, our findings suggest that it is not necessary to exclude participants with low IQ, especially for low cognitive load tasks, and inclusion of these participants will have the benefit of increased generalization of the findings.

\section{Additional files}

Additional file 1: Table S1. Participant demographics and study enrollment. For each participant, sex, KBIT-2 verbal standard score, non-verbal standard score and IQ composite are reported. An "X" was 
placed in the appropriate column for each fMRI task in which a participant was enrolled.

Additional file 2: Table S2. All subjects region of interest correlation coefficients. S.2A. All subjects region of interest correlation coefficients: Auditory Mirror Neuron System fMRI study. S.2B. All subjects region of interest correlation coefficients: Music-Noise fMRI study. S.2C. All subjects region of interest correlation coefficients: Faces fMRI study. S.2D. All subjects region of interest correlation coefficients: Images fMRI study

\section{Abbreviations}

Aud-MNS: Auditory mirror neuron system study; BOLD: Blood oxygen leveldependent; fMRI: Functional magnetic resonance imaging; KBIT-2: Kaufman Brief Intelligence Test, Second Edition; ROI: Region of interest; T1W: T1weighted; WS: Williams syndrome.

\section{Competing interests}

The authors declare that they have no competing interests.

\section{Authors' contributions}

JRP, SNA, JUB, and TATW conducted the neuroimaging studies. EMD conceived of the study, and TATW primarily designed the study. JRP participated in the design of the study, conducted the analyses, and drafted the manuscript. EMD and TATW helped to draft the manuscript. SNA and JUB edited the manuscript. All authors read and approved the final manuscript.

\section{Acknowledgements}

We would like to thank all study volunteers for their time and willingness to participate in this research. We are grateful for the sponsors of the Williams Syndrome Music Camp, including the Vanderbilt Kennedy Center for Research on Human Development, the Academy of Country Music's Lifting Lives program, and the Vanderbilt Blair School of Music. We thank and acknowledge the research staff of the Williams Syndrome Music Camp who administered the KBIT-2 IQ assessments, including Elizabeth Roof, Research Coordinator. This research was supported in part by funding from the $\mathrm{NIH}$ Roadmap for Medical Research Postdoctoral Fellowship - Biobehavioral Intervention Training Program T32 MH075883 to TATW, National Institute of Mental Health K01-MH083052 to JUB, NIH/NICHD P30-HD15052, National Center for Research Resources - Vanderbilt CTSA Grant (1-UL-RR024975), NIH/ NIA 1P30AG038445-01, a Vanderbilt University Discovery Grant, a Vanderbilt Kennedy Center Hobbs Discovery Grant, and the Vanderbilt University Institute of Imaging Science. Portions of this work were presented at the Society for Neuroscience Annual Meeting, Washington, DC, 2011, the Gatlinburg Conference on Intellectual and Developmental Disabilities, San Antonio, TX, 2010, and the Memphis Biolmaging Symposium, Memphis, TN 2010.

\section{Author details}

${ }^{1}$ Interdisciplinary Studies in Neuroimaging of Neurodevelopmental Disorders, Vanderbilt University Medical Center, Nashville, TN, USA. ${ }^{2}$ Vanderbilt Kennedy Center for Research on Human Development, Vanderbilt University, Nashville, TN, USA. " Vanderbilt Brain Institute, Neuroscience Graduate Program, Vanderbilt University, Nashville, TN, USA. ${ }^{4}$ Department of Psychology, Vanderbilt University, Nashville, TN, USA. ${ }^{5}$ Department of Psychiatry, Vanderbilt University School of Medicine, Nashville, TN, USA. ${ }^{6}$ Department of Psychology and Human Development, Peabody College|, Vanderbilt University, Nashville, TN, USA. ${ }^{7}$ Center for Human Genetics Research, Department of Molecular Physiology and Biophysics, Vanderbilt Institute of Imaging Science, Vanderbilt University Medical Center, Nashville, TN, USA.

Received: 23 May 2012 Accepted: 13 September 2012 Published: 26 October 2012

\section{References}

1. Bayes M, Magano LF, Rivera N, Flores R, Perez Jurado LA: Mutational mechanisms of Williams-Beuren syndrome deletions. Am J Hum Genet 2003, 73:131-151.

2. Strømme P, Bjømstad PG, Ramstad K: Prevalence Estimation of Williams Syndrome. J Child Neurol 2002, 17:269-271.
3. Bellugi U, Lichtenberger L, Jones W, Lai Z, St George M: I. The neurocognitive profile of Williams Syndrome: a complex pattern of strengths and weaknesses. J Cogn Neurosci 2000, Suppl 1:7-29.

4. Mervis CB, Robinson BF, Bertrand J, Morris CA, Klein-Tasman BP, Armstrong SC: The Williams syndrome cognitive profile. Brain Cogn 2000, 44:604-628.

5. Schmitt JE, Eliez S, Warsofsky IS, Bellugi U, Reiss AL: Corpus callosum morphology of Williams syndrome: relation to genetics and behavior. Dev Med Child Neurol 2001, 43:155-159.

6. Udwin O, Yule W: A cognitive and behavioural phenotype in Williams syndrome. J Clin Exp Neuropsychol 1991, 13:232-244.

7. Bellugi U, Adolphs R, Cassady C, Chiles M: Towards the neural basis for hypersociability in a genetic syndrome. Neuroreport 1999, 10:1653-1657.

8. Dykens EM: Anxiety, fears, and phobias in persons with Williams syndrome. Dev Neuropsychol 2003, 23:291-316.

9. Dykens EM, Rosner BA: Refining behavioral phenotypes: personality-motivation in Williams and Prader-Willi syndromes. Am J Ment Retard 1999, 104:158-169.

10. Doyle TF, Bellugi U, Korenberg JR, Graham J: "Everybody in the world is my friend" hypersociability in young children with Williams syndrome. Am J Med Genet A 2004, 124A:263-273.

11. Gosch A, Pankau R: Personality characteristics and behaviour problems in individuals of different ages with Williams syndrome. Dev Med Child Neurol 1997, 39:527-533.

12. Elsabbagh $\mathrm{M}$, Cohen $\mathrm{H}$, Cohen M, Rosen $\mathrm{S}$, Karmiloff-Smith $\mathrm{A}$ : Severity of hyperacusis predicts individual differences in speech perception in Williams Syndrome. J Intellect Disabil Res 2011, 55:563-571.

13. Gothelf $D$, Farber N, Raveh E, Apter A, Attias J: Hyperacusis in Williams syndrome: characteristics and associated neuroaudiologic abnormalities. Neurology 2006, 66:390-395.

14. Levitin DJ, Bellugi U: Musical Abilities in Individuals with Williams Syndrome. Music Perception 1998, 15:357-389.

15. Levitin DJ, Cole K, Chiles M, Lai Z, Lincoln A, Bellugi U: Characterizing the musical phenotype in individuals with Williams Syndrome. Child Neuropsychol 2004, 10:223-247.

16. Levitin DJ, Cole K, Lincoln A, Bellugi U: Aversion, awareness, and attraction: investigating claims of hyperacusis in the Williams syndrome phenotype. J Child Psychol Psychiatry 2005, 46:514-523.

17. Nigam A, Samuel PR: Hyperacusis and Williams syndrome. J Laryngol Otol 1994, 108:494-496.

18. Blomberg S, Rosander M, Andersson G: Fears, hyperacusis and musicality in Williams syndrome. Res Dev Disabil 2006, 27:668-680.

19. John $A E$, Mervis CB: Sensory modulation impairments in children with Williams syndrome. Am J Med Genet C Semin Med Genet 2010, 154C:266-276

20. Woodruff-Borden J, Kistler DJ, Henderson DR, Crawford NA, Mervis CB: Longitudinal course of anxiety in children and adolescents with Williams syndrome. Am J Med Genet C Semin Med Genet 2010, 154C:277-290

21. Elison S, Stinton C, Howlin P: Health and social outcomes in adults with Williams syndrome: findings from cross-sectional and longitudinal cohorts. Res Dev Disabil 2010, 31:587-599.

22. Howlin $\mathrm{P}$, Davies $\mathrm{M}, \mathrm{Udwin} \mathrm{O}$ : Cognitive functioning in adults with Williams syndrome. J Child Psychol Psychiatry 1998, 39:183-189.

23. Martens MA, Wilson SJ, Reutens DC: Research Review: Williams syndrome: a critical review of the cognitive, behavioral, and neuroanatomical phenotype. J Child Psychol Psychiatry 2008, 49:576-608.

24. Searcy YM, Lincoln AJ, Rose FE, Klima ES, Bavar N, Korenberg JR: The relationship between age and IQ in adults with Williams syndrome. Am J Ment Retard 2004, 109:231-236.

25. Boddaert N, Mochel F, Meresse I, Seidenwurm D, Cachia A, Brunelle F, Lyonnet S, Zilbovicius M: Parieto-occipital grey matter abnormalities in children with Williams syndrome. Neuroimage 2006, 30:721-725.

26. Don AJ, Schellenberg GE, Rourke BP: Music and language skills of children with Williams syndrome. Child Neuropsychol 1999, 5:154-170.

27. Bellugi U, Bihrle A, Jernigan T, Trauner D, Doherty S: Neuropsychological, neurological, and neuroanatomical profile of Williams syndrome. Am J Med Genet 1990, 37:115-125.

28. Golarai G, Hong S, Haas BW, Galaburda AM, Mills DL, Bellugi U, Grill-Spector $\mathrm{K}$, Reiss AL: The fusiform face area is enlarged in Williams syndrome. J Neurosci 2010, 30:6700-6712. 
29. Haas BW, Mills D, Yam A, Hoeft F, Bellugi U, Reiss A: Genetic influences on sociability: heightened amygdala reactivity and event-related responses to positive social stimuli in Williams syndrome. J Neurosci 2009, 29:1132-1139.

30. Levitin DJ, Menon V, Schmitt JE, Eliez S, White CD, Glover GH, Kadis J, Korenberg JR, Bellugi U, Reiss AL: Neural correlates of auditory perception in Williams syndrome: an fMRI study. Neuroimage 2003, 18:74-82.

31. Meyer-Lindenberg A, Kohn P, Mervis CB, Kippenhan JS, Olsen RK, Morris CA, Berman KF: Neural basis of genetically determined visuospatial construction deficit in Williams syndrome. Neuron 2004, 43:623-631.

32. Meyer-Lindenberg A, Hariri AR, Munoz KE, Mervis CB, Mattay VS, Morris CA, Berman KF: Neural correlates of genetically abnormal social cognition in Williams syndrome. Nat Neurosci 2005, 8:991-993.

33. Meyer-Lindenberg A: Functional, structural, and metabolic abnormalities of the hippocampal formation in Williams syndrome. J Clin Invest 2005, 115:1888-1895.

34. Mimura M, Hoeft F, Kato M, Kobayashi N, Sheau K, Piggot J, Mills D, Galaburda A, Korenberg JR, Bellugi U, Reiss AL: A preliminary study of orbitofrontal activation and hypersociability in Williams Syndrome. J Neurodev Disord 2010, 2:93-98.

35. Mobbs D, Garrett AS, Menon V, Rose FE, Bellugi U, Reiss AL: Anomalous brain activation during face and gaze processing in Williams syndrome. Neurology 2004, 62:2070-2076.

36. Mobbs D, Eckert MA, Mills D, Korenberg J, Bellugi U, Galaburda AM, Reiss AL: Frontostriatal dysfunction during response inhibition in Williams syndrome. Biol Psychiatry 2007, 62:256-261

37. Mobbs D, Eckert MA, Menon V, Mills D, Korenberg J, Galaburda AM, Rose FE, Bellugi U, Reiss AL: Reduced parietal and visual cortical activation during global processing in Williams syndrome. Dev Med Child Neurol 2007, 49:433-438.

38. Muñoz KE, Meyer-Lindenberg A, Hariri AR, Mervis CB, Mattay VS, Morris CA, Berman KF: Abnormalities in neural processing of emotional stimuli in Williams syndrome vary according to social vs. non-social content. Neuroimage 2010, 50:340-346.

39. O'Hearn K, Roth JK, Courtney SM, Luna B, Street W, Terwillinger R, Landau B: Object recognition in Williams syndrome: uneven ventral stream activation. Dev Sci 2011, 14:549-565.

40. Olsen RK, Kippenhan JS, Japee S, Kohn P, Mervis CB, Saad ZS, Morris CA, Meyer-Lindenberg A, Berman KF: Retinotopically defined primary visual cortex in Williams syndrome. Brain 2009, 132:635-644.

41. Paul BM, Snyder AZ, Haist F, Raichle ME, Bellugi U, Stiles J: Amygdala response to faces parallels social behavior in Williams syndrome. Soc Cogn Affect Neurosci 2009, 4:278-285.

42. Sarpal D, Buchsbaum BR, Kohn PD, Kippenhan JS, Mervis CB, Morris CA, Meyer-Lindenberg A, Berman KF: A genetic model for understanding higher order visual processing: functional interactions of the ventra visual stream in Williams syndrome. Cereb Cortex 2008, 18:2402-2409.

43. Thornton-Wells TA, Cannistraci CJ, Anderson AW, Kim C-Y, Eapen M, Gore JC, Blake R, Dykens EM: Auditory attraction: activation of visual cortex by music and sound in Williams syndrome. Am J Intellect Dev Disabil 2010, 115:172-189.

44. Thornton-Wells TA, Avery SN, Blackford JU: Using novel control groups to dissect the amygdala's role in Williams Syndrome. Dev Cogn Neurosci 2011, 1:295-304

45. Wengenroth M, Blatow M, Bendszus M, Schneider P: Leftward lateralization of auditory cortex underlies holistic sound perception in Williams syndrome. PLoS One 2010, 5:e12326.

46. Kaufman AS, Kaufman NL: Kaufman Brief Intelligence Test. 2nd edition. London: Pearson; 2004

47. Mervis CB, Kistler DJ, John AE, Morris CA: Longitudinal assessment of intellectual abilities of children with Williams syndrome: multilevel modeling of performance on the Kaufman Brief Intelligence Test-Second Edition. Am J Intellect Dev Disabil 2012, 117:134-155.

48. Gazzola V, Aziz-Zadeh L, Keysers C: Empathy and the somatotopic auditory mirror system in humans. Curr Biol 2006, 16:1824-1829.

49. Galati G, Committeri G, Spitoni G, Aprile T, Di Russo F, Pitzalis S, Pizzamiglio L: A selective representation of the meaning of actions in the auditory mirror system. Neuroimage 2008, 40:1274-1286.

50. Schwartz CE, Wright Cl, Shin LM, Kagan J, Whalen PJ, McMullin KG, Rauch SL: Differential amygdalar response to novel versus newly familiar neutral faces: a functional MRI probe developed for studying inhibited temperament. Biol Psychiatry 2003, 53:854-862.

51. Wright Cl, Martis B, Schwartz CE, Shin LM, Fischer HH, McMullin K, Rauch SL: Novelty responses and differential effects of order in the amygdala, substantia innominata, and inferior temporal cortex. Neuroimage 2003, 18:660-669.

52. Lee KH, Choi YY, Gray JR, Cho SH, Chae J-H, Lee S, Kim K: Neural correlates of superior intelligence: Stronger recruitment of posterior parietal cortex. Neuroimage 2006, 29:578-586.

53. Gray JR, Chabris CF, Braver TS: Neural mechanisms of general fluid intelligence. Nat Neurosci 2003, 6:316-322.

54. Graham S, Jiang J, Manning V, Nejad AB, Zhisheng K, Salleh SR, Golay X, Berne Yl, McKenna PJ: IQ-related fMRI differences during cognitive set shifting. Cereb Cortex 2010, 20:641-649.

doi:10.1186/1866-1955-4-24

Cite this article as: Pryweller et al:: The effect of intellectual ability on functional activation in a neurodevelopmental disorder: preliminary evidence from multiple fMRI studies in Williams syndrome. Journal of Neurodevelopmental Disorders 2012 4:24.

\section{Submit your next manuscript to BioMed Central and take full advantage of:}

- Convenient online submission

- Thorough peer review

- No space constraints or color figure charges

- Immediate publication on acceptance

- Inclusion in PubMed, CAS, Scopus and Google Scholar

- Research which is freely available for redistribution 